\title{
AVALIAÇÃO EM CAMPO DE UMA SEMEADORA-ADUBADORA PARA SEMEADURA DE MILHO DE ALTA DENSIDADE
}

\author{
EVANDRO CHARTUNI MANTOVANI ${ }^{1}$, JOSE CARLOS CRUZ ${ }^{1}$, \\ ANTONIO CARLOS DE OLIVEIRA ${ }^{1}$
}

${ }^{1}$ Embrapa Milho e Sorgo, Sete Lagoas, MG, Brasil, evandro.mantovani@embrapa.br, josecarlos.cruz@embrapa.br, antoniocarlos.oliveira@embrapa.br

Revista Brasileira de Milho e Sorgo, v.14, n.1, p. 38-48, 2015

\begin{abstract}
RESUMO - Com a evolução dos níveis tecnológicos utilizados pelos produtores mais tecnificados no Brasil, aumentou também a preocupação com a plantabilidade. Uma melhor distribuição das sementes em semeaduras de milho de alta densidade, tanto em profundidade quanto em relação à distância entre as plantas nas linhas e entrelinhas, são fatores essenciais para aumentos significativos na produtividade do milho. O objetivo deste trabalho é avaliar o desempenho de uma semeadora-adubadora para o estabelecimento da cultura do milho com alta densidade de semeadura. Nesse contexto, testes comparativos entre quatro dosadores, utilizados alternadamente em uma semeadora de milho com sistema de semeadura direta, foram realizados em uma área experimental de 7,2 $\mathrm{mil} \mathrm{m}^{2}$ na Embrapa Milho e Sorgo, em Sete Lagoas, MG. Para o estabelecimento do estande de alta densidade (75.000 plantas ha $\left.{ }^{-1}\right)$, os seguintes fatores foram estudados: três velocidades de semeadura $\left(5,7 \mathrm{e} 9 \mathrm{~km} \mathrm{~h}^{-1}\right)$; quatro dosadores (pneumático, disco, titanium e rampflow); e dois espaçamentos entrelinhas $(0,45$ e $0,90 \mathrm{~m})$. A utilização da maior velocidade de semeadura aumentou a porcentagem de duplos e falhas, independentemente do espaçamento e do tipo de dosador, assim como a dispersão da distribuição longitudinal de sementes, no espaçamento de $0,45 \mathrm{~m}$.
\end{abstract}

Palavras-chave: Zea mays L.; plantabilidade de milho; testes de campo; distribuição longitudinal.

\section{FIELD EVALUATION OF A SEEDER FOR HIGH DENSITY MAYZE PLANTING}

\begin{abstract}
The progress of the technology levels used by the most technified farmers in Brazil increased the concern about plantability. A better distribution of the seeds at sowing in high density maize crop, regarding depth, distance between plants and inter-row spacing are essential to significantly increase yield. The objective of this study was to evaluate the performance of a seeder for the placement of a high density maize crop. In this context, comparative tests of four dosers of a maize seeder in no-tillage system were conducted in an experimental area of $7.2 \mathrm{mil} \mathrm{m}^{2}$ at Embrapa Maize and Sorghum, in Sete Lagoas, Minas Gerais. In order to establish a high density stand (75,000 plants $\left.\mathrm{ha}^{-1}\right)$, the following factors were studied: three planting speeds $\left(5,7\right.$ and $\left.9 \mathrm{~km} \mathrm{~h}^{-1}\right)$, four seed dosers (pneumatic, disc, titanium and rampflow) and two row spacing $(0.45 \mathrm{~m}$ and $0.90 \mathrm{~m})$. The use of high-speed planting increased the percentage of doubles and failures regardless of the row spacing and type of doser as well as the dispersion of the longitudinal distribution of seeds, spaced $0.45 \mathrm{~m}$.
\end{abstract}

Key words: Zea mays L.; field tests; maize planting; longitudinal distribution; plantability. 
Com a evolução dos níveis tecnológicos utilizados pelos produtores mais tecnificados no Brasil, aumentou também a preocupação com a plantabilidade. Ou seja, uma melhor distribuição das sementes em semeaduras de milho de alta densidade, tanto em profundidade quanto em relação à distância entre as plantas nas linhas e entrelinhas, são fatores essenciais para aumentos significativos na produtividade do milho.

$\mathrm{O}$ aumento do número de plantas por hectare e a redução do espaçamento da cultura do milho têm ocorrido nas principais regiões produtoras brasileiras. Isso tem sido possível devido ao material genético das cultivares lançadas no mercado e também pela necessidade de os agricultores aumentarem a produtividade. A predominância de híbridos simples com sementes graúdas no mercado atual tem sido uma tendência, e isso muda muito com o formato arredondado e de menor comprimento, facilitando a regulagem dos dosadores de distribuição a disco. De acordo com Cruz et al. (2007), o rendimento de grãos cresceu linearmente com o aumento da densidade de plantas em ambos os espaçamentos (0,50 e 0,80 m). Contudo, no espaçamento de $0,50 \mathrm{~m}$ entrelinhas, a produtividade apresentou uma maior amplitude, porque passou de 40.000 para 77.500 plantas ha-1 ${ }^{-1}$ do que no espaçamento de $0,80 \mathrm{~m}$, indicando que a redução de espaçamento é mais vantajosa quando se utilizam maiores densidades de plantas. O desenvolvimento de híbridos tolerantes a altas densidades, o aumento no número de herbicidas para o controle seletivo de plantas daninhas em pós-emergência e a maior agilidade da indústria de máquinas agrícolas no desenvolvimento de equipamentos adaptados ao cultivo do milho com linhas mais próximas são fatores que favorecem o incremento da adoção dessa prática cultural (Silva, 2005).

Nesse aspecto, a necessidade de estabelecer estande adequado de plantas tem sido sempre um dos grandes desafios na implantação da cultura. Os equipamentos atuais de semeadura, convencionais e de semeadura direta, evoluíram muito desde a última década. Praticamente todos os sistemas de distribuição de sementes, discos, dedos prensores e pneumática estão disponíveis no mercado nacional. Entretanto, percebe-se que o sistema de discos continua sendo o mais usado na grande maioria das propriedades brasileiras, principalmente pelo menor valor de custo. Nesse sentido, vale ressaltar a importância de uma boa classificação de sementes para a regulagem desse sistema de distribuição de sementes.

O conjunto semeadora-adubadora convencional é constituído de quatro sistemas importantes: distribuição de sementes; distribuição de adubo; profundidade de semeadura; e compactação da semente. Se for em semeadura direta, adiciona-se mais um sistema: o de corte de palhada. É imprescindível que cada um dos sistemas tenha um bom desempenho para que a semeadura seja bem feita. A falha de um ou de mais de um desses sistemas pode comprometer o conjunto e dificultar a implantação de uma determinada cultura no estabelecimento do estande recomendado.

$\mathrm{O}$ assunto plantabilidade de milho teve um grande avanço, principalmente pelas contribuições dos testes de semeadoras-adubadoras realizados na Embrapa Milho e Sorgo no período de 1986-1992, em conjunto com a Abimaq (Mantovani et al. (1992) e (1999), Kurachi et al. (1989), no Departamento de Engenharia Agrícola - DEA/IAC, Casão Junior et al. (2003), no Iapar, e em outras instituições, para solução dos problemas tecnológicos dos equipamentos de semeadura, que realmente impediam o estabelecimento dos estandes técnicos recomendados entre 40-60 mil plantas ha- ${ }^{-1}$. Com o desenvolvimento de novas cultivares e a melhoria das técnicas de manejo do solo planta $^{-1}$, os agricultores estão implantando novas lavouras 
de milho com estande de alta densidade, de até 80 mil plantas ha-1 ${ }^{-1}$ e com a redução do espaçamento entrelinhas. Entretanto, nessa faixa de alta densidade de semeadura, os problemas de plantabilidade começaram a ser evidenciados, necessitando uma atenção especial para saber se novamente o problema é tecnológico ou de conhecimento técnico.

O objetivo deste trabalho foi avaliar o desempenho de uma semeadora-adubadora no campo para o estabelecimento de uma cultura de milho de alta densidade.

Como objetivo específico, o desempenho da semeadora-adubadora foi avaliado em três velocidades de semeadura, com quatro sistemas de distribuição de sementes e em dois espaçamentos entrelinhas.

\section{Material e Métodos}

Este trabalho foi desenvolvido na Embrapa Milho e Sorgo, no município de Sete Lagoas, MG, cuja latitude e longitude são respectivamente, $19^{\circ} 28^{\prime}$ $\mathrm{S}$ e $44^{\circ} 15^{\prime} \mathrm{W}$.Gw e altitude de $732 \mathrm{~m}$, em um latossolo vermelho escuro, álico de textura argilosa.

Os testes de avaliação de desempenho no campo foram realizados em parceria com as empresas Marchesan e Apollo Agrícola, com a metodologia da Embrapa Milho e Sorgo.

Nesse contexto, testes comparativos entre quatro dosadores de semeadoras de milho, em sistema de semeadura direta, foram realizados em uma área experimental de 7,2 mil m², na Embrapa Milho e Sorgo, em Sete Lagoas.

O delineamento experimental utilizado para análise do experimento foi blocos ao acaso, com parcelas sub-subdivididas, com três repetições, sendo, na parcela, espaçamento $(0,45$ e $0,90 \mathrm{~m})$; na subparcela, velocidade $\left(5,7\right.$ e $\left.9 \mathrm{~km} \mathrm{~h}^{-1}\right)$, e na sub-subparcela, dosadores (disco, pneumático, titanium e rampflow). As análises de variância foram feitas para estande, \% de duplos, $\%$ de falhas e $\%$ de aceitáveis. Foi estudada a dispersão entre plantas ou distribuição longitudinal no intervalo aceitável.

Uma semeadora-adubadora PST 4 FLEX, com dez linhas de semeadura, sendo cinco linhas com discos e cinco linhas com sistema de distribuição pneumática, foi utilizada com quatro dosadores, em dois sistemas de distribuição: um pneumático; e um de disco convencional, em sistema de semeadura direto. Além dos discos convencionais que acompanham a PST4 FLEX, dois dosadores foram testados:

um disco, denominado rampflow; um conjunto dosador a disco, denominado titanium;

Sensores eletrônicos foram instalados nas dez linhas da semeadora-adubadora, no sistema distribuidor de semente e de adubo, para garantir o seu adequado funcionamento, durante os testes de campo.

A população utilizada para a realização dos testes foi de 75 mil plantas por hectare, em dois espaçamentos entrelinhas, 0,45 e $0,90 \mathrm{~m}$, justificados para facilitar a operacionalidade da semeadura. Considerando o poder germinativo da semente e perdas ao longo de desenvolvimento da cultura, a quantidade de semente/ metro foi de 4 e 8 sementes/m, para os espaçamentos 0,45 e $0,90 \mathrm{~m}$, respectivamente, com um total de 82.325 sementes por hectare. A semeadora-adubadora em teste foi montada na barra porta ferramentas para trabalhar com dez linhas, com o espaçamento de 0,45 $\mathrm{m}$. Dessa forma, o espaçamento de $0,90 \mathrm{~m}$ era obtido apenas com o isolamento de cinco linhas intercaladas, o que facilitava muito os testes de campo.

A distribuição de adubo e semente foi avaliada, nos testes de campo, em três velocidades de semeadura, 5, 7 e $9 \mathrm{~km} \mathrm{~h}^{-1}$. Para os testes de adubo, a 
recomendação foi de $400 \mathrm{~kg} \mathrm{ha}^{-1}$ da formulação 4-148 e os testes de distribuição foram realizados ao lado da área de semeadura, com parcelas de $30 \mathrm{~m}$ de comprimento, para não atrapalhar os testes de plantabilidade, onde o plantio de milho deverá ser avaliado até a colheita. O sistema de distribuidor de adubo é do tipo rosca sem fim e o adubo foi coletado em sacos plásticos, fixados na saída de cada linha da semeadora, para coleta do fertilizante, no percurso de $30 \mathrm{~m}$, nas respectivas velocidades e em três repetições.

O híbrido simples de milho Pioneer 30F53 foi utilizado nos testes, para regulagem dos discos e do sistema pneumático, e os testes de análise de qualidade foram realizados no Laboratório de Análise de Sementes da Embrapa Milho e Sorgo, com poder germinativo de $98 \%$ e envelhecimento acelerado de $99 \%$.

A semeadora-adubadora PST4 FLEX foi regulada, seguindo a orientação da empresa fabricante, com os sistemas disco e pneumático e os dosadores rampflow e titanium também foram regulados pela empresa que os disponibilizou para a adequada quantidade de sementes por hectare.

Para garantir a emergência e a germinação da semente, um sistema de irrigação foi montado na área, que, imediatamente após a semeadura, iniciou a irrigação para garantir a quantidade de água necessária para os testes de plantabilidade.

A profundidade de semeadura foi medida 15 dias após a emergência das plantas, cortando-se a parte superior e medindo-se do ponto cortado até a semente.

Para facilitar a avaliação do estande e da distância longitudinal das sementes, as medições foram feitas com as plantas que emergiram, dentro de uma área de $10 \mathrm{~m}$ lineares. Como a marcação iniciava-se na primeira planta, media-se a distância da planta anterior até a primeira planta e finalizava-se, medindo-a até a última planta dentro desse intervalo. Sendo assim, nas avaliações, as plantas representam as sementes que foram distribuídas pela semeadora-adubadora para facilitar a contagem do estande e a distribuição longitudinal nos espaçamentos aceitáveis, duplo e falhas mencionados abaixo.

A norma da ABNT (1996) considera espaçamentos aceitáveis todas as sementes que se encontram entre 0,5 a 1,5 vez o espaçamento médio estabelecido. Os valores fora desse limite são considerados como falha, quando estão acima de 1,5 vez o espaçamento médio, e como duplos os que estão abaixo de $0,5 \mathrm{vez}$ o espaçamento médio. De acordo com Kurachi et al. (1989), a porcentagem de ocorrências nesse intervalo entre 0,5 a 1,5 vez o espaçamento médio é considerada como semeio adequado realizado pela semeadora e com espaçamentos normais/aceitáveis do ponto de vista da DEA/IAC.

A dispersão das distâncias entre plantas, nas linhas, foi medida pelo Desvio Médio Absoluto (DMA), definido como:

$$
D M A=\frac{\sum_{i=1}^{n}\left|d_{i}-r e f\right|}{n}
$$

onde, $d_{i}=$ distância observada entre as plantas; ref $=$ distância de referência, que é igual a 15 para o espaçamento de $0,90 \mathrm{~m}$ e 30 para o espaçamento de $0,45 \mathrm{~m}$;

$$
\mathrm{n}=\text { número de observações. }
$$

\section{Resultados e Discussão}

Os resultados da distribuição de adubo são mostrados nas Figuras 1 e 2 e indicam os comportamentos das linhas de semeadura, nas três velocidades de semeadura, com 0,90 e $0,45 \mathrm{~m}$ de 
espaçamento entrelinhas, respectivamente. A quantidade de adubo distribuída varia entre 364 e $432 \mathrm{~kg}$ $\mathrm{ha}^{-1}$, com uma variação de $15,7 \%$ entre o menor e o maior valores, com um valor médio de $389 \mathrm{~kg} \mathrm{ha}^{-1}$, para o espaçamento de $0,90 \mathrm{~m}$, e de 378 a $392,45 \mathrm{~kg}$ $\mathrm{ha}^{-1}$, com uma variação de $17,33 \%$, com um valor médio de $386,44 \mathrm{~kg} \mathrm{ha}^{-1}$, para o espaçamento de 0,45 m. A análise estatística mostrou diferença significativa, a 5,0\% de probabilidade, para o espaçamento entrelinhas. O espaçamento de $0,45 \mathrm{~m}$ superou o de 0,90 $\mathrm{m}$, independentemente da velocidade de semeadura, com média de $394,36 \mathrm{~kg} \mathrm{ha}^{-1}$, valor próximo da recomendação, indicando que a semeadora-adubadora tem uma melhor distribuição ou estabilidade de distribuição de adubo quando está operando com todas as dez linhas.

Entretanto, a Figura 2 mostra que a variação de velocidade em cada linha, com espaçamento de 0,45 m, não foi significativa estatisticamente, indicando a estabilidade das linhas na distribuição de adubo, o que é bem próximo da recomendação de $400 \mathrm{~kg} \mathrm{ha}{ }^{-1}$.

As Figuras 3 e 4 mostram o comportamento do sistema de controle de profundidade da semeadora-adubadora PST 4 FLEX. Inicialmente, a semeadora foi regulada para semear em uma profundidade entre 3 e $5 \mathrm{~cm}$. Entretanto, após o início das operações, no espaçamento entrelinhas de $0,45 \mathrm{~m}$, percebeu-se que ela estava colocando a semente bem superficialmente, entre 2 e $4 \mathrm{~cm}$, o que foi corrigido para o espaçamento de $0,90 \mathrm{~m}$. Como a operação não pode ser interrompida quando se inicia o teste, optou-se por fazer a regulagem nas parcelas de $0,90 \mathrm{~m}$ e avaliar a estabilidade do sistema de controle de profundidade. Como pode ser visto nas Figuras 3 e 4, mesmo ocorrendo uma oscilação na profundidade com a variação de velocidade, com maior destaque para a velocidade de $5 \mathrm{~km} \mathrm{~h}^{-1}$, o sistema é eficiente e estável, mantendo a semente dentro dos limites aceitáveis, de 2 a $4 \mathrm{~cm}$, nas parcelas, com espaçamento entrelinhas de 0,45 $\mathrm{m}$ e de 3 a $5 \mathrm{~cm}$ nas parcelas de $0,90 \mathrm{~m}$. Em todas as linhas avaliadas, verifica-se que a velocidade de 5 $\mathrm{km} \mathrm{h}^{-1}$ apresentou a maior profundidade de semeio, sem ter uma explicação adequada para essa situação. Entretanto, ao verificar nas Figuras 3 e 4 que todas as linhas ficaram dentro do espaçamento planejado para as três velocidades, não há motivo para se preocupar, aprovando, dessa forma, o sistema de rodas de controle de profundidade.

Os valores obtidos para a população de plantas para a semeadora-adubadora são apresentados nas Figuras 5 e 6 . Observa-se que nenhum dos tratamentos, com o espaçamento de 0,90 m, alcançou a recomendação agronômica da população desejada (75.000 plantas ha $\mathrm{h}^{-1}$ ) e diferente do espaçamento de 0,45 m, que ficou muito próximo da recomendação, com uma variação muito pequena entre dosadores.

$\mathrm{O}$ estande de plantas inicial nas Figuras 5 e 6 indica o comportamento dos quatro tipos de dosadores utilizados para a semeadura nas três velocidades. No espaçamento de $0,45 \mathrm{~m}$, o número de plantas ha-1 varia entre 70.370 e 81.484 plantas ha- $^{-1}$, com uma variação de $13,6 \%$ entre o menor e o maior valores e um valor médio de 76.111 plantas ha ${ }^{-1}$. Do mesmo modo, essa redução do estande ocorre para o espaçamento de $0,90 \mathrm{~m}$, mantendo-se abaixo de 75.000 plantas ha $^{-1}$, com uma variação 61.111 a 73.333 plantas ha ${ }^{-1}$; entre os valores máximo e mínimo, existe uma variação de $16,7 \%$ e um valor médio de 67.253 plantas ha ${ }^{-1}$.

A análise de variância dos valores obtidos para estande na Tabela 1 mostrou significância, ao nível de 5\%, para espaçamento, velocidade e tipo de dosador. 


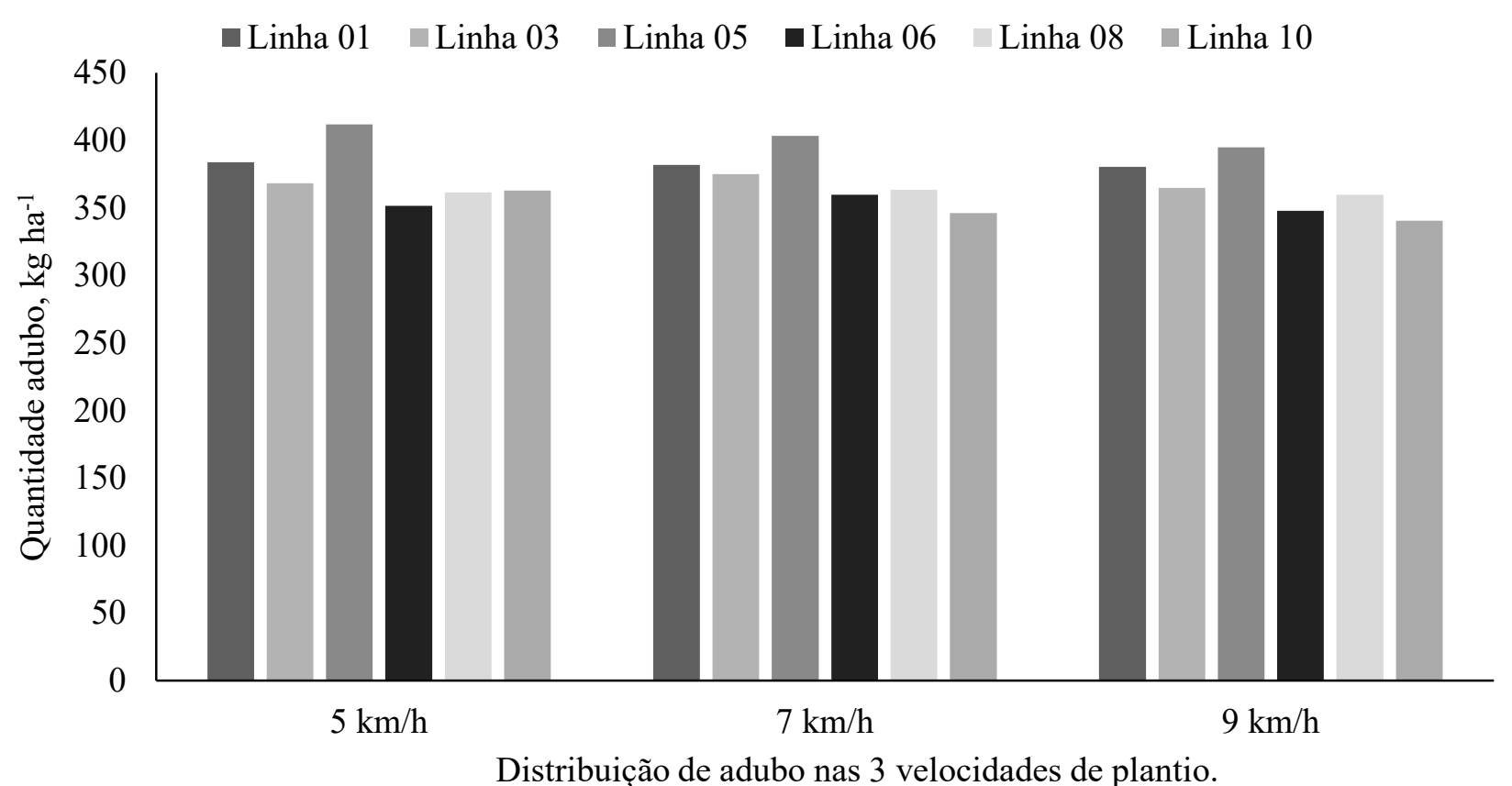

FIGURA 1. Avaliação da distribuição de adubo da Semeadora Adubadora PST4 FLEX. Recomendação de adubação: $400 \mathrm{~kg} \mathrm{ha}^{-1}$. Espaçamento entre linhas de $0,90 \mathrm{~m}$.

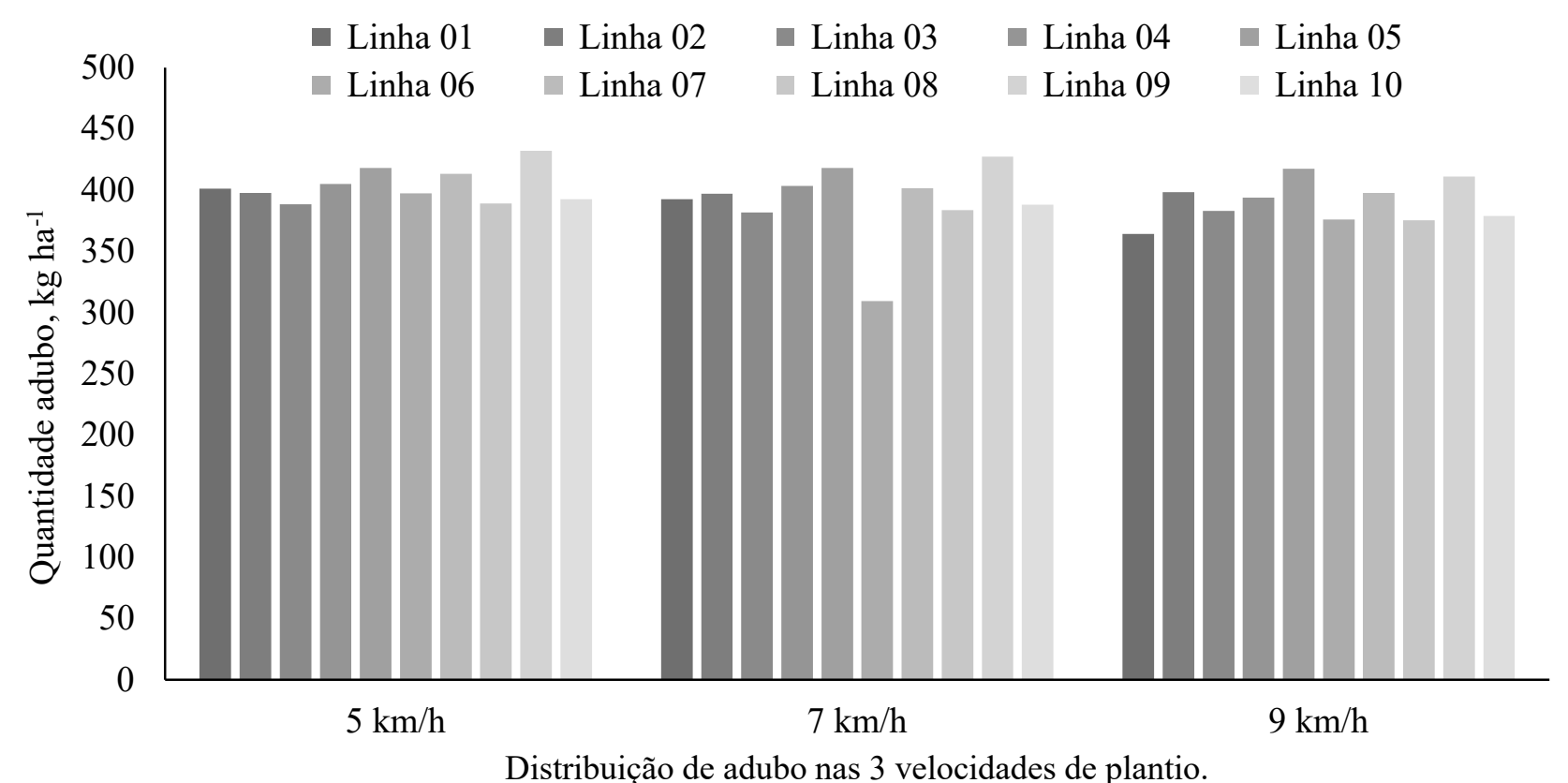

FIGURA 2. Avaliação da distribuição de adubo da Semeadora Adubadora PST4 FLEX. Recomendação de adubação: $400 \mathrm{~kg} \mathrm{ha}^{-1}$. Espaçamento entre linhas de 0,45 m. 


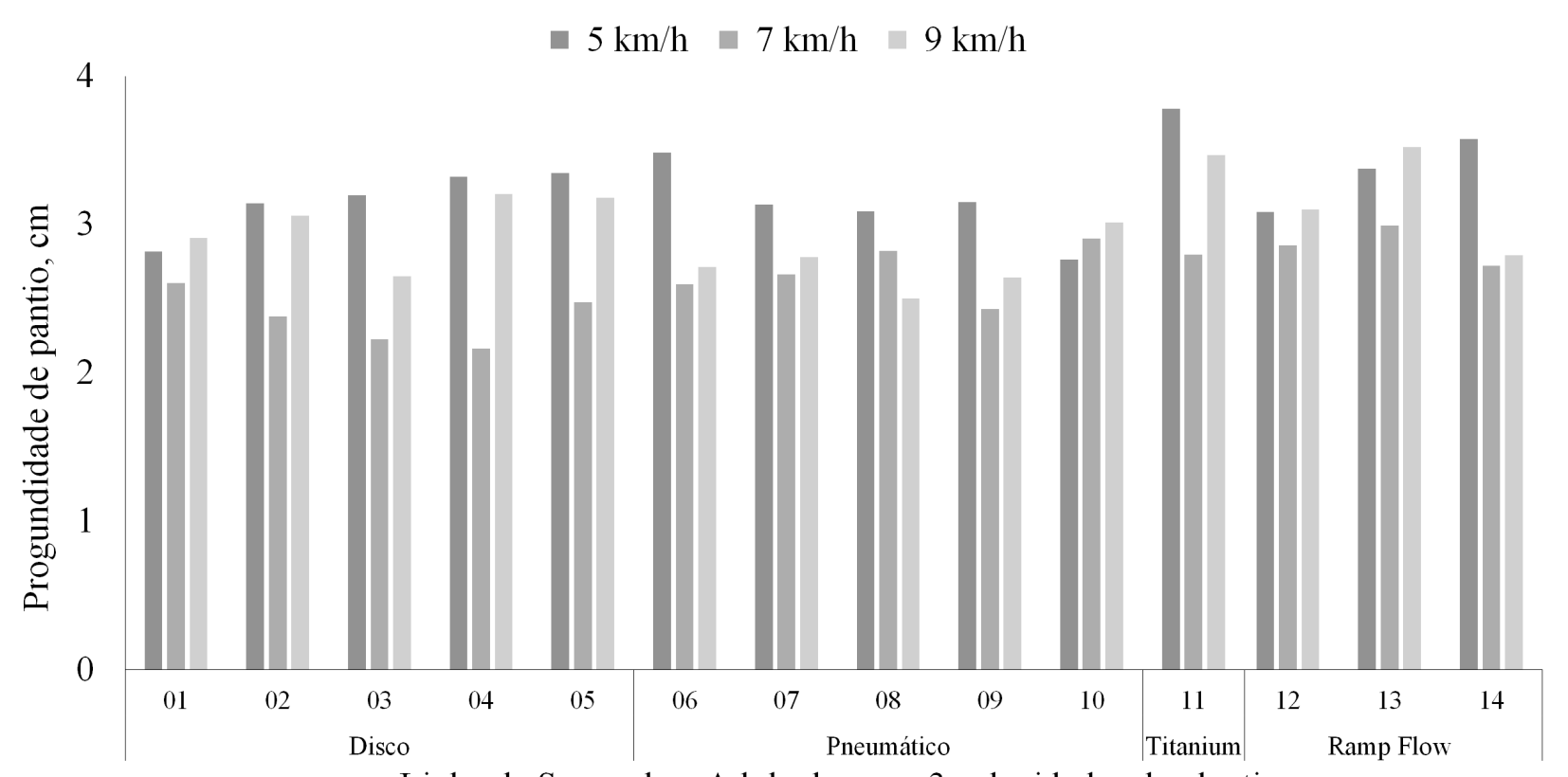

Linha de Semeadora Adubadora em 3 velocidades de plantio

FIGURA 3. Avaliação da profundidade de plantio da Semeadura Adubadora PST4 FLEX. Recomendação de profundidade: entre 3 e $5 \mathrm{~cm}$. Espaçamento entre linhas de 0,45 m.

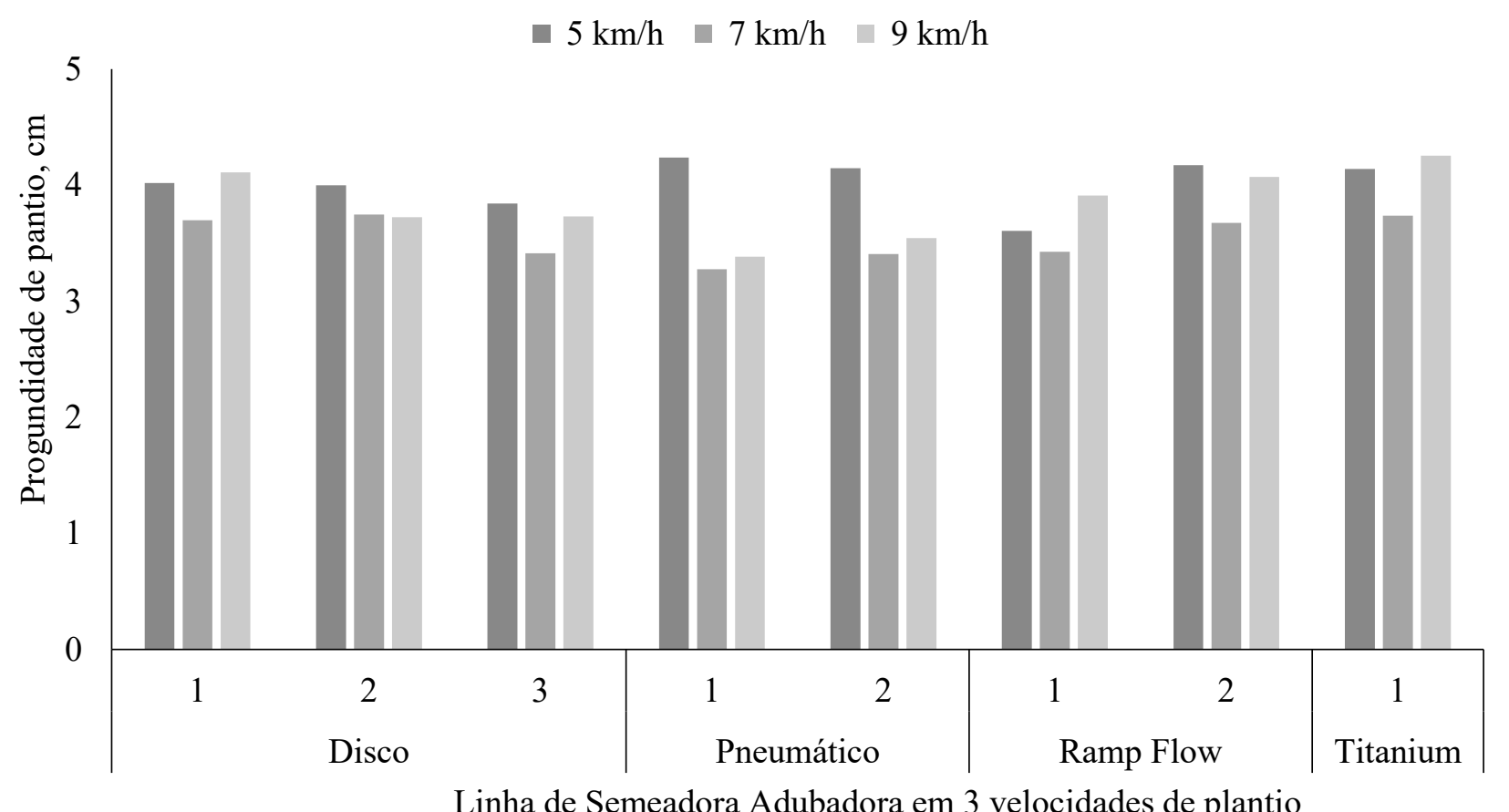

FIGURA 4. Avaliação da profundidade de plantio da Semeadura Adubadora PST4 FLEX. Recomendação de profundidade: entre 3 e $5 \mathrm{~cm}$. Espaçamento entre linhas de $0,90 \mathrm{~m}$. 
Os testes de média para espaçamento, mostrados na Tabela 2, indicam que não há diferença significativa para duplos e significativos para falhas e aceitáveis, com valores percentuais de falhas de 16,52 e 7,55, e aceitáveis de 71,22 e 80,45, nos espaçamentos entrelinhas de 0,90 e $0,45 \mathrm{~m}$, respectivamente. Para velocidade, indicam que há diferença significativa para duplos, falhas e aceitáveis, com uma redução expressiva de espaçamento aceitáveis de $83,34 \%$, na velocidade de $5 \mathrm{~km} \mathrm{~h}^{-1}$, para $67,65 \%$, na velocidade de $9 \mathrm{~km} \mathrm{~h}^{-1}$. Para tipo de dosador, indicam que há diferença significativa para duplos e aceitáveis entre o dosador disco e o titanium e não há diferença entre dosadores para falhas. A diferença para duplos entre o dosador disco e o titanium é quase o dobro, 8,51 e $16,02 \%$, e, no caso dos aceitáveis, houve uma redução de 79,12 para 72,73\%.

Para avaliar a dispersão da distribuição longitudinal no intervalo de espaçamentos aceitáveis, foi realizado um estudo calculando-se o Desvio Médio Absoluto, que é mostrado na Tabela 3. Independentemente do tipo de dosador, o espaçamento de $0,45 \mathrm{~m}$ apresentou uma maior dispersão para a velocidade de $9 \mathrm{~km} \mathrm{~h}^{-1}$, com valores de DMA de 10,89 a 12,54 .

A velocidade de $9 \mathrm{~km} \mathrm{~h}^{-1}$ promoveu uma redução significativa para os espaçamentos aceitáveis entre plântulas para os diferentes dosadores, com o aumento substancial de duplos e falhas afetando o estande final. Moreira et al.. (1978) mencionam que, se a semente tiver mais tempo disponível para ser liberada, o desempenho da máquina tende a ser melhor.

A semeadora com dosadores titanium, rampflow e pneumática obteve resultados mais satisfatórios, para as velocidades de 5 e $7 \mathrm{~km} \mathrm{~h}^{-1}$, com um maior percentual de espaçamentos aceitáveis e menor de falhas e duplos. Observou-se que o aumento de velocidade periférica do disco dosador aumenta os espaçamentos duplos e falhas. Esses resultados estão em consonância com os descritos por Bisognin et al. (2009), Furlani et al. (1999), Silva et al. (2000) e Mahl et al. (2004).

\section{Conclusão}

A semeadora-adubadora tem uma melhor distribuição ou estabilidade de distribuição de adubo quando está operando com todas as dez linhas.

O sistema de controle de profundidade é eficiente e estável, mantendo a semente dentro dos limites aceitáveis.

Os testes de campo para avaliação de uma semeadora-adubadora utilizada para o estabelecimento de uma cultura de milho de alta densidade obtiveram um bom desempenho quando operada nos limites de velocidades de 5 a $7 \mathrm{~km} \mathrm{~h}^{-1}$, utilizando-se dosadores pneumáticos, titanium e rampflow no espaçamento entrelinhas de $0,45 \mathrm{~m}$.

\section{Agradecimentos}

Empresa Marchesan, pela parceria no trabalho e cessão da semeadora-adubadora PST 3 FLEX, de semeadura direta, de dez linhas, com metade das linhas a disco e metade com o sistema pneumático.

Apollo Agrícola, pela parceria e cessão dos discos rampflow e titanium.

Empresa Pró-Solus, pela contribuição e montagem dos sensores de controle eletrônico de queda de semente e adubo em cada linha da semeadora-adubadora.

Embrapa Milho e Sorgo, pela infraestrutura e pessoal de apoio na condução e na avaliação dos dados de campo. 


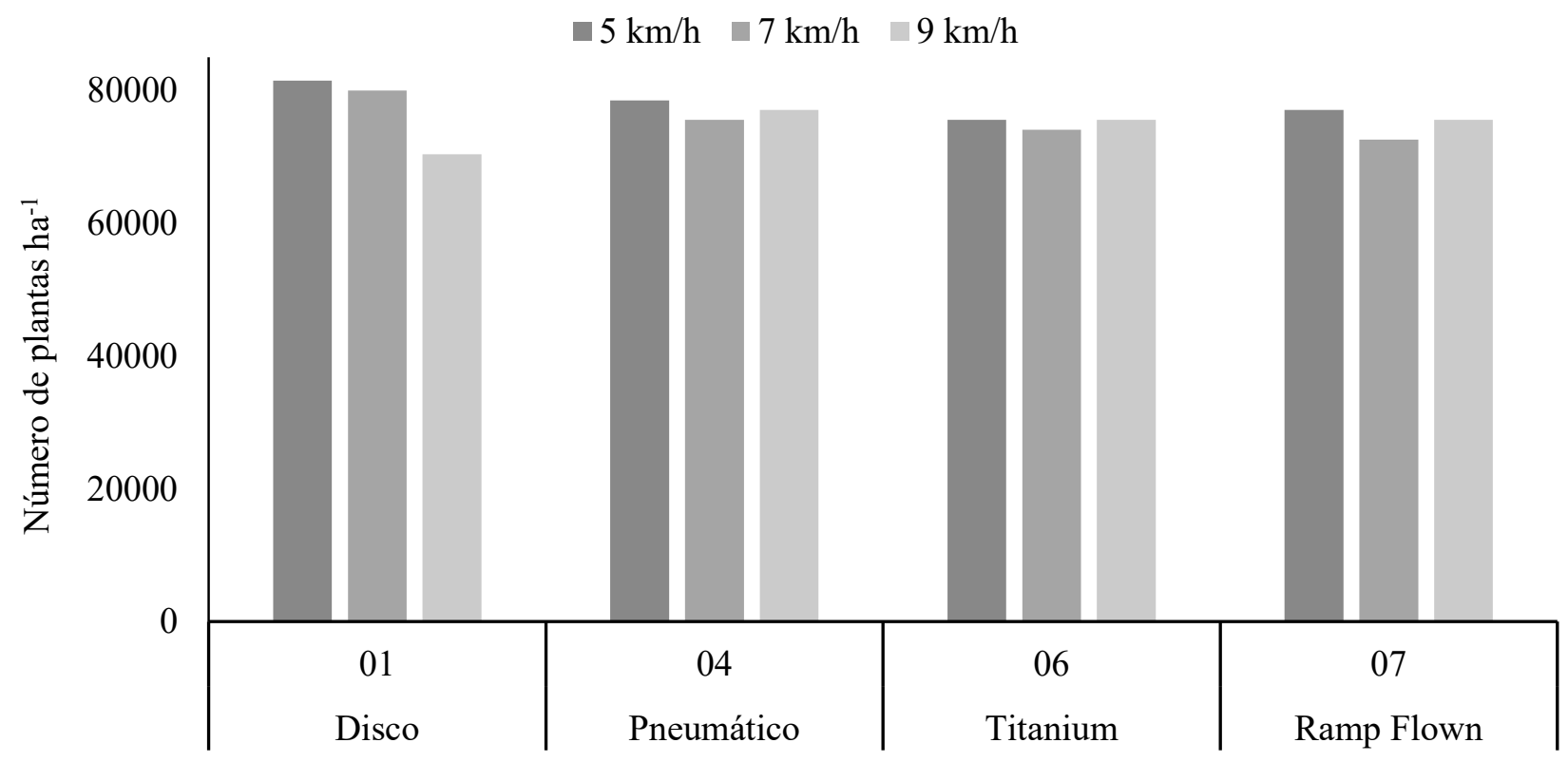

Tipos de dosadores, nas 3 velocidades de plantio

FIGURA 5. Estande de plantas inicial semeado por 4 dosadores e 3 velocidades de plantio. Estande recomendado: 75.000 plantas $^{-1} \mathrm{a}^{-1}$ Espaçamento entre plantas: 0,45 m

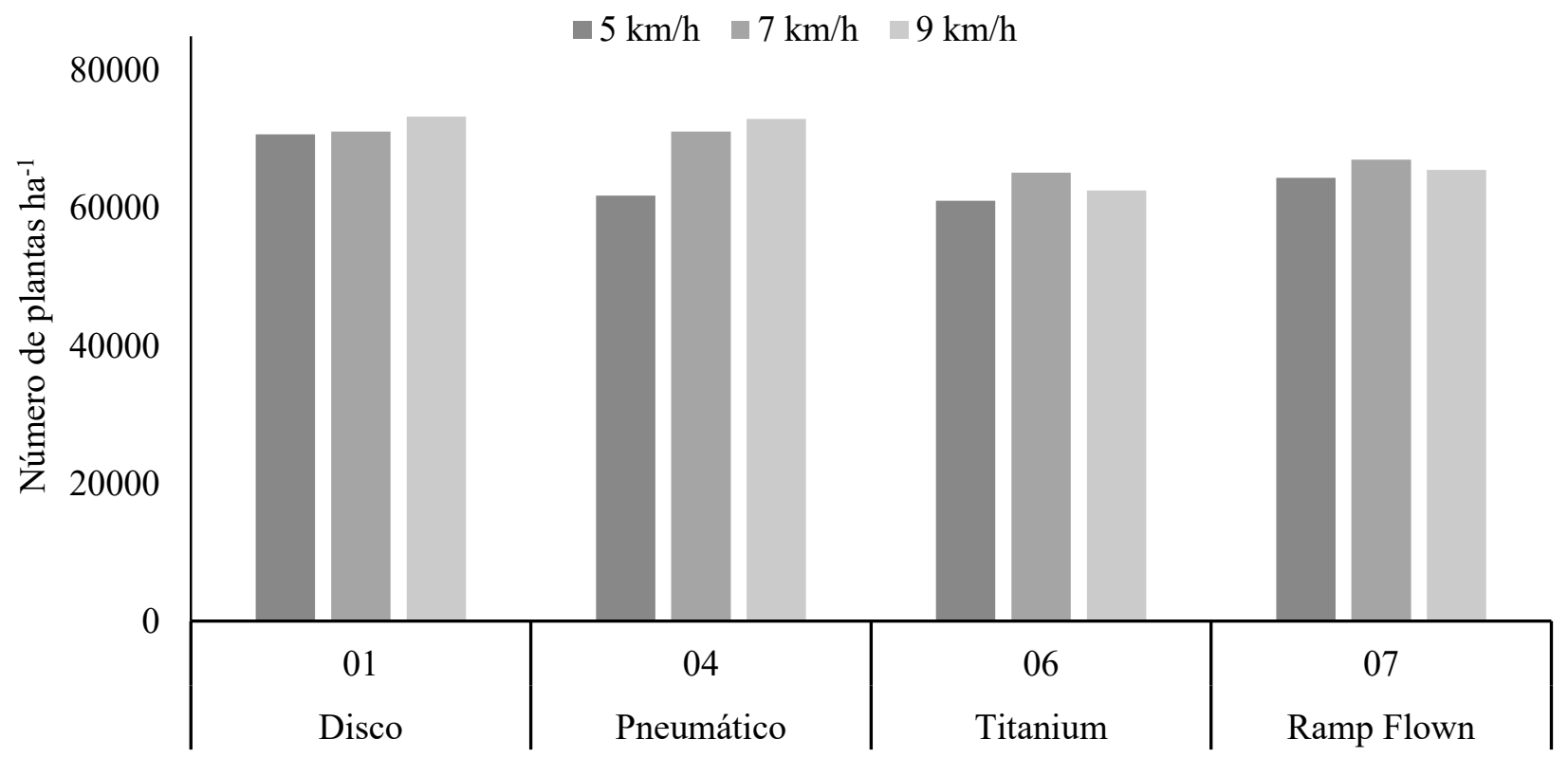

Tipos de Dosadores, nas 3 velocidades de plantio

FIGURA 6. Estande de plantas inicial semeado por 4 dosadores e 3 velocidades de plantio. Estande recomendado: 75.000 plantas ha-1 ${ }^{-1}$ Espaçamento entre plantas: 0,90 m 
Referências

ASSOCIAÇÃO BRASILEIRA DE NORMAS TÉCNICAS. Projeto de Norma 04:015:06-010. Semeadora e distribuidoras de fertilizantes e corretivos- terminologia: definições. São Paulo, 1996. 23 p.

CRUZ, J. C.; PEREIRA, F. T. F.; PEREIRA FILHO, I. A.; OLIVEIRA, A. C. de; MAGALHAES, P. C. Resposta de cultivares de milho à variação em espaçamento e densidade. Revista Brasileira de Milho e Sorgo, Sete Lagoas, v. 6, n. 1, p. 60-73, 2007.

FURLANI, C. E. A.; LOPES, A.; ABRAHÃO, F. Z.; LEITE, M. A. S. Características da cultura do milho (Zea mays L.) em função do tipo de preparo do solo e da velocidade de semeadura. Engenharia Agrícola, Jaboticabal, v. 19, n. 2, p.177-186, 1999

GARCIA, L.C.; JASPER, R.; JASPER, M.; FORNARI, A. J.; BLUM, J. Influência da velocidade de deslocamento na semeadura do milho. Engenharia Agrícola, Jaboticabal, v.26, n.2, p.520-527, 2006.

JASPER, R.; JASPER, M.; GARCIA, L. C. Seleção de sementes de milho durante a simulação da semeadura com disco perfurado horizontal. Engenharia Agrícola, Jaboticabal, v.26, n.2, p.434-441, 2006. Disponível em: $<$ http://www.scielo.br.ez103.periodicos. capes.gov.br/scielo.php?script $=$ sci_art text\&pid=S010069162006000200011 $\& \operatorname{lng}=$ en\&nrm=iso $>$ Acesso em: 8 mai. 2009.

KURACHI, S. A. H.; COSTA, J. A. S; BERNARDI, J. A.; COELHO, J. L. D.; SILVEIRA, G. M. Avaliação tecnológica de semeadoras e/ou adubadoras: tratamento de dados de ensaios e regularidade de distribuição longitudinal de sementes. Bragantia, Campinas, v. 4, n. 2, p. 249-69162004000100017\&lng=en\&nrm= iso>. Acesso em: 8 mai. 2009. dói: 10.1590/ S0100-69162004000100017

MAHL, D.; GAMEROII, C. A.; BENEZ, S. H.; FURLANI, C. E. A.; SILVA, A. R. B. Demanda energética e eficiência da distribuição de sementes de milho sob variação de velocidade e condição de solo. Engenharia Agrícola, Jaboticabal, v. 24, n.1, p. 150-157, 2004.

MANTOVANI, E. C.; BERTAUX, S.; ROCHA, F. E. C. Avaliação de Eficiência Operacional de Diferentes Semeadoras-Adubadoras de Milho.

Pesquisa Agropecuária Brasileira, Brasília, DF, v. 27, n. 12, p. 1579-1586, dez 1992.

MANTOVANI, E. C.; MANTOVANI, B. H. M.; CRUZ, I.; MEWES, W. L. C.; OLIVEIRA, A. C. Desempenho de dois sistemas distribuidores de sementes utilizados em semeadoras de milho. Pesquisa Agropecuária Brasileira, Brasília, DF, v. 34, n. 1, p. 93-98, 1999.

MOREIRA, C. A.; PEREIRA, J. C. V. N. A.; MENEZES, J. F.; COSTA, J. A. S. Desempenho de mecanismos dosadoresdistribuidores de sementes em plantadeiras adubadeiras. Campinas: IAC, 1978. 22 p. (Circular, 90).

SILVA, A. K. Redução do espaçamento entrelinhas na cultura do milho. In: REUNIÃO TÉCNICA CATARINENSE DE MILHO E FEIJÃO, 5., 2005, Chapecó. Resumos expandidos... Chapecó: Epagri: Cepaf, 2005. p. 27-30.

SILVA, J. G.; KLUTHCOUSKI, J.; SILVEIRA, P. M. Desempenho de uma semeadora-adubadora no estabelecimento e na produtividade da cultura do milho sob semeadura direto. 
Scientia. 262,1989.

SILVA, P. R. F. da; ARGENTA, G.; REZERA, F. Resposta de híbridos de milho irrigado à densidade de plantas em três épocas de semeadura. Pesquisa Agropecuária Brasileira, Brasília, DF, v. 34,n. 4, p. 585592, 2005.
TEIXEIRA, S. S; REIS, A. V. dos; MACHADO, A. L. T.; BISOGNIN, A.; SILVEIRA, H. A. T. da. Distribuição longitudinal de sementes de milho com dosador de disco horizontal operando com uma ou duas saídas de sementes. Ciência Rural, Santa Maria, v. 39, n. 8 p. $2417-2421,2009$. 